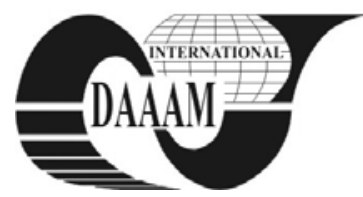

\title{
MIND LAB EDUCATIONAL PROGRAM AN EXCELLENT TOOL FOR MANAGERIAL SKILLS DEVELOPMENT
}

\author{
LUT, D[ina] M[aria] \& MICULESCU, M[arius] N[icolae]
}

\begin{abstract}
The paper presents results of a study conducted in the frame of a research project aiming to adapt the International Mind Lab educational program for managerial skills development and also for promote it on the management training market. This research project is a bold attempt, to contribute to development of cognitive, social and emotional skills that are essential for a performing manager, through a unique way - strategy games.
\end{abstract}

Key words: Mind Lab, managerial skills, strategy games, learning process, interdisciplinary transfer

\section{INTRODUCTION}

The manager profession is a very complex profession, requiring for a person to be effective in many activities. There is an old controversy between experts: always ask the question: "Managers are born or can be created through education and training?" We believe (like many other experts, in fact), that while talent and natural inclinations play undoubtedly an important role, becoming manager is the result of a professional and personal transformation process.

Based on these considerations and based on the managerial skills mix (designed by Daniel Katz, American specialist), including cognitive skills, communication skills and technical skills, needed for every manager, according to managerial level), (Peterson \& Van Fleet, 2004), we identified in the Mind Lab educational program an excellent tool to educate and develop the thinking of adults with major professional responsibilities.

The International program Mind Lab is an educational program that was originally designed for the personal development of children between 4 and 14 years. It supports the systematic training of skills in three developmental areas: cognitive skills, social skills, and skills in the field of emotional intelligence. The Mind Lab Method is a unique and innovative approach for the development and training of thinking abilities and life skills through strategy games.

Mind Lab's unique concept is based upon the notion that strategy games serve as a high-powered educational tool. Strategy games contribute to the improvement of cognitive skills and to creating an awareness of thinking processes. They also help the learner to better cope with emotional and social situations. The game-playing experience is at once enjoyable, captivating, and exciting - thus kindling great motivation and enthusiasm among students and serving as the foundation for a deep learning process (Welter, 2008).

This educational program was originally developed in Israel in 1994, by Ehud Shachar and Dan Gendelman, both experts in educational sciences. Today, Mind Lab's research team includes experts in science education, strategic games, psychologists, and engineering and computing experts (Mind Lab Group, 1994).

\section{OBJECTIVES AND ACTIVITIES OF THE RESEARCH PROJECT}

Identifying potential and usability of this program for adults to develop essential skills in leadership work, we established the following specific objectives of the project:
1. Analyzing the Mind Lab program in order to adapt it for use in developing managerial skills

To achieve this, we did the research and documentation in several directions, with the following results:

- Theoretical analysis of the program

The Mind Lab educational program is built on a strong theoretical basis in science education and psychology, making continual reference to the theories of renowned scientists and researchers such as Dewey, Gardner, Perkins and Feuerstein and applying them in educational practice. (Ben-Hur, 1994), (Dewey, 1997), (Feuerstein, 2010), (Perkins, 2009).

- Analysis of program objectives in the development of managerial skills

These objectives are: awareness of cognitive processes, cognitive learning skills, developing social skills and emotional intelligence, interdisciplinary transfer.

- Analysis of Mind Lab’s learning process

The educational process consists of 3 powerful and research-proven stages: participants engage in game-playing; learning the Mind Lab thinking tools; the transfer to real-life situations.

- Adapting abstract patterns of thought and overlapping with real situations encountered in daily management activities, such as: strategic and operational planning, conflict management, resource management, making decisions process, etc.

2. Setting up a study group composed of companies (operating in various fields) in which to test the Mind Lab program;

In order to test the adapted version of the program, we selected a total of seven companies (medium-sized and large companies), operating in different areas (trade, financial and banking, business consultancy). The Mind Lab program has been made known in the business environment through various media: sites used to promote courses, business magazines, work-shops, etc. The companies that agreed to be included in the survey are part of the study group that experienced the Mind Lab educational program and with their help we studied its impact and its efficiency in developing managerial skills.

3. Presenting the Mind Lab program to the selected companies

To achieve this objective we organized presentation sessions of the program, in which we described and analyzed, together with the participants, the main components of the program: objectives, theoretical foundations, methodology, its benefits and various other aspects. Also, at this stage, following discussions with the participants, we reviewed the program in order to adapt it for the concrete needs of the participating companies. Following this stage, and knowing the contents and benefits of the program, the surveyed companies could identify the real needs of training and could determine exactly what are the managers or what are the managerial levels at which it is useful to implement the program.

4. Testing the program for selected managers in the study group companies 
This is the most complex and important stage of the research project that involves the effective application of specific learning methods and learning strategies of the program for selected managers in the study group companies. This means attending the three methodological stages:

- Stage 1: involve the managers in the study group in a thinking game (selected from those included in the program);

In this first stage, the selected managers learn one of the many strategy games present in the program, and then go on to play in small groups. The facilitator provides them with a game kit and explains the game strategies underlying the thinking concepts. There are many examples of cognitive, emotional and social skills strengthened by the Mind Lab Method and very essential for managers: problem solving, decision making, forward planning, logical thinking; managing emotions, patience, perseverance, learning from failures, self discipline; teamwork and cooperation, dealing with competition, communicating efficiently.

- Stage 2: using one or more Mind Lab thinking methods to improve cognitive skills, emotional and social skills;

In this second stage, the facilitator and the managers summarize the game-playing session with the help of a thinking model. This model relates to cognitive processes triggered by game-playing (for example, identifying and dealing with a problem, or having to make a difficult decision), or to emotional or social processes (for example, recognizing having made a mistake or the need to cooperate as part of a group).

- Stage 3: transfer learned methods to applications in daily management activities.

To consolidate, every day of the course ended with a reflective summary on the activity throughout the day. The facilitator and managers examine the game patterns and then initiate a discussion relating to relevant real-life situations. This helped the managers to reflect on ideas learned by comparing them with their previous thinking. In so doing, the managers succeed in applying the knowledge derived from the game experience to other aspects of their professional lives.

\section{RESEARCH RESULTS}

After testing the Mind Lab program for selected managers in the study group, companies have assessed the impact of using this program within each surveyed company.

To analyze the impact of Mind Lab program use on managerial performance, we compared two sets of results: the professional results of managers, found after the first performance appraisal process of the post program period and professional results of latest performance appraisal process before participation of the managers at the Mind Lab program.

The obtained results were encouraging: all the managers participants in the program - admitted to have improved their abstract and strategic thinking and also their communication skills, teamwork skills and emotional skills.

The results come from the first managers performance appraisal process, after their participation in the program, confirmed this. The learning of the Mind Lab problem-solving models significantly improve managers' strategic thinking skills. The managers who learned Mind Lab abstract models succeeded in transferring the knowledge acquired to new fields, and the improvement in these new fields was even greater than in the original game.

\section{DISCUSSIONS AND CONCLUSIONS}

The efficacy of the Mind Lab Method has been put to the test in a number of comparative research projects carried out in conjunction with senior researchers, most notably with Professor Donald Green of Yale University. The research verifies that the Mind Lab Method significantly improves thinking abilities and life skills.

In Romania, the Mind Lab program is used only in a relatively small scale for children's education. We believe that the Mind Lab Method can be very efficient for Romanian managers training and can help them to develop strategic thinking skills so necessary in daily managerial activities.

The application of content and skills learned in one setting to another is considered by many researchers to be one of the most important learning abilities. The Mind Lab Method establishes an organizing base for many aspects of life. Through this method, the ability to identify links between different fields of human thinking and activity is developed, and this consequently enables the transfer of knowledge to other fields.

\section{FURTHER RESEARCH}

Results from trials conducted were discussed with the license owner for this program, who commissioned this study.

The Mind Lab program was tested in a small number of companies, and the study has no national expansion. However, we believe that Mind Lab program can be a very effective tool for the development of the three categories of managerial skills: cognitive skills, communication skills and emotional skills. Therefore, this program can be promoted on the managerial training market. Moreover, the results of this study were forwarded to businesses environment in the Timis county of Romania in order to be promoted, and also to academia, in order to provide a starting point in a partnership between the two parties.

\section{ACKNOWLEDGEMENTS}

This paper is the result of research in the frame of the R\&D project with the theme: "Study on the analysis of effectiveness and impact of the Mind Lab educational program usage, for managerial skills development, in order to promote the program on the management training market." The project is running under contract between "Dimitrie Cantemir" Christian University from Bucharest and a private economic operator from Timisoara - SC BIZEQ SRL (the license owner for this program).

\section{REFERENCES}

Ben-Hur, M. (editor). (1994). On Feuerstein's Instrumental Enrichment: A Collection, IRI/SkyLight Training and Publishing, Inc., ISBN 0-932935-76-1, IL

Dewey, J. (1997). Experience \& Education, Touchstone Rockefeller Center, ISBN 978-0-684-83828-1, New York

Feuerstein, R. (2010). Beyond Smarter: Mediated Learning and the Brain's Capacity for Change, Teachers College Press, ISBN 978-0-8077-5118-3, New York

Perkins, D. N. (2009), Making Learning Whole: How Seven Principles of Teaching Can Transform Education, Jossey Bass A Wiley Imprint, ISBN 978-0-470-38452-7, San Francisco

Peterson, T.O.; Van Fleet, D. (2004). "The ongoing legacy of R.L. Katz: An updated typology of management skills", Management Decision, Vol. 42, Issue 10, pp.1297-1308, ISSN 0025-1747, USA

Welter, B. (2008). MindLab: A Place to Think, AuthorHouse, ISBN 978-1-4343-7916-0, Bloomington, IN

*** (1994) http://www.mindlab-group.com - Mind Lab Group, Accessed on: 2011-01-12 